\title{
Campomelic dysplasia associated with a de novo 2q;17q reciprocal translocation
}

\author{
I D Young, J M Zuccollo, E L Maltby, N J Broderick
}

\begin{abstract}
A phenotypically female fetus with campomelic dysplasia and a de novo reciprocal translocation, $46, X Y, t(2 ; 17)(q 35 ; q 23-$ $24)$, is presented. This is the second case of campomelic dysplasia in which a rearrangement involving the long arm of chromosome 17 has been identified, indicating that this is likely to be the site of the campomelic dysplasia locus.
\end{abstract}

Campomelic dysplasia (CD) is a rare disorder characterised by shortening and bowing of the lower limbs, hypoplastic scapulae, cleft palate, tracheomalacia, and bilateral talipes equinovarus. Other anomalies may include a high forehead, micrognathia, low set ears, narrow thorax, and cardiac defects. Sex reversal occurs in a proportion of affected XY subjects. The overall prognosis is gloomy with a high incidence of death in the neonatal period and poor intellectual development in survivors.

The underlying mode of inheritance has not been fully established although autosomal recessive transmission is generally accepted as the most likely underlying mechanism. Maraia $e t a l^{2}$ have recently reported an affected female infant with a de novo paracentric inversion of $17 \mathrm{q}$ and have postulated that one of the breakpoints may indicate the site of the $\mathrm{CD}$ locus. We now present details of another case with a de novo rearrangement involving $17 \mathrm{q}$.

Department of

Clinical Genetics, City

Hospital, Hucknall

Road, Nottingham

NG5 1 PB.

I D Young

Department of

Histopathology,

Queen's Medical

Centre, Nottingham.

J M Zuccollo

Centre for Human Genetics, Sheffield.

E L Maltby

Department of Radiology, City Hospital, Nottingham.

N J Broderick

Correspondence to Dr Young.

Received for publication

17 August 1991.

Accepted for publication

27 August 1991. appeared normal and the external genitalia were normal female. Internal examination showed no visceral abnormalities with normal uterus, tubes, and ovaries (fig 2). Histology of the tibiae and fibulae showed normal metaphyses with remodelling at the points of angulation.

Radiographs of the fetus (fig 3) showed angulation at the junction of the upper third and lower two-thirds of both femora with symmetrical shortening. The tibiae were also shortened with acute angulation at the junction of the upper two-thirds and lower third of each bone. Both fibulae were also symmetrically shortened and slightly bowed.

\section{CYTOGENETIC STUDIES}

Analysis of cultured amniocytes obtained at amniocentesis undertaken shortly before termination of pregnancy showed a male karyotype with an apparently balanced reciprocal translocation involving one chromosome 2 and one chromosome 17 in all cells analysed (fig 4).

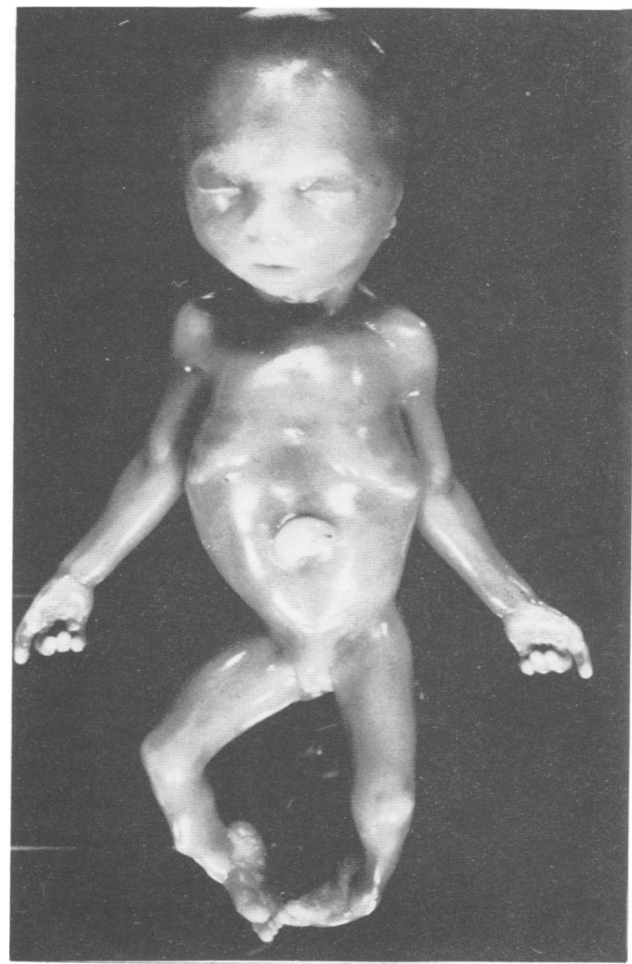

Figure 1 Postmortem view of the fetus showing micrognathia with bowing of the lower limbs and bilateral talipes. 


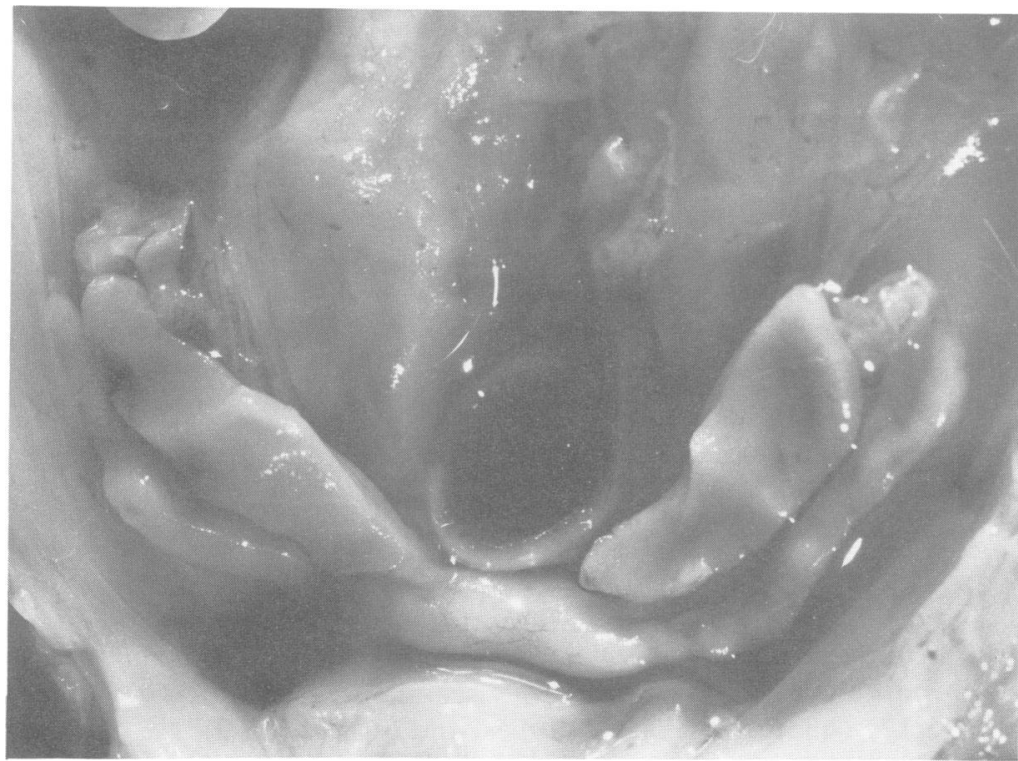

Figure 2 Internal genitalia consisting of normal ovaries, fallopian tubes, and uterus.

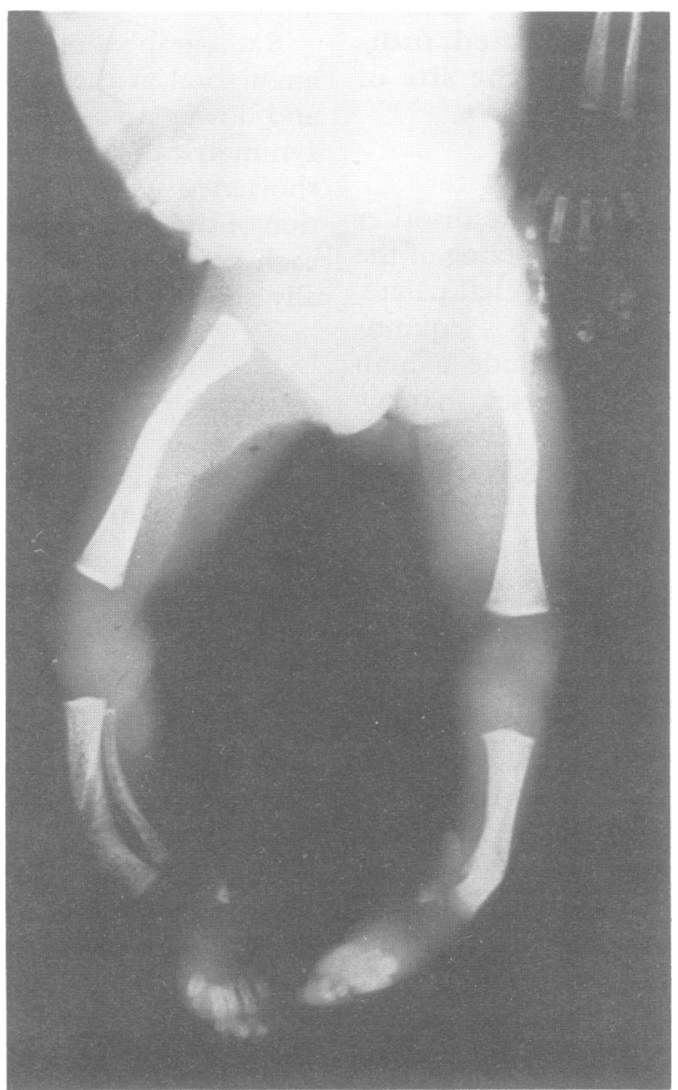

Figure 3 Radiograph of lower limbs showing bowing and angulation of long bones.
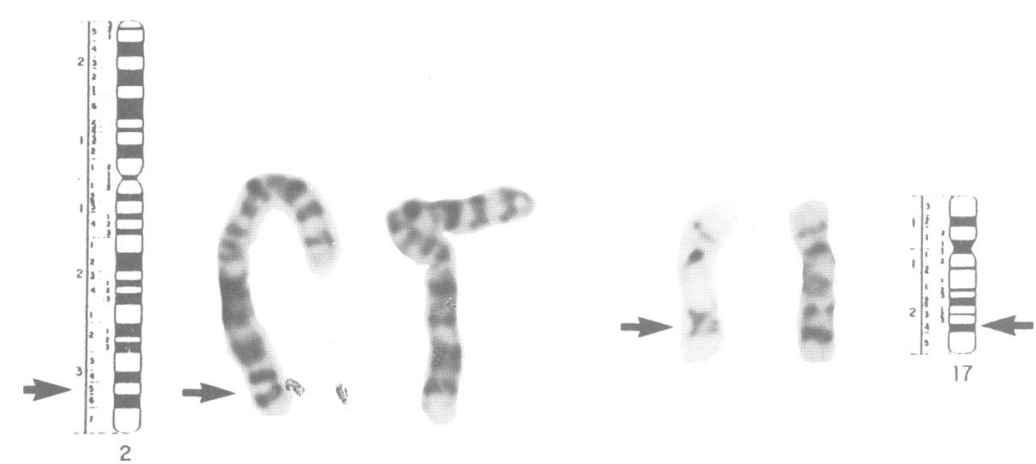

Figure 4 Photograph of translocation between chromosomes 2 and 17. The breakpoints are indicated by arrows; the normal homologues are on the left of each pair.
The breakpoints were interpreted as $2 \mathrm{q} 35$ and $17 \mathrm{q} 23-24$, that is, $46, \mathrm{XY}, \mathrm{t}(2 ; 17)$ (q35;q23-24). This was confirmed on analysis of cultured fibroblasts grown from a post delivery skin biopsy. Parental chromosomes were analysed using cultured lymphocytes and found to be normal.

\section{Discussion}

The clinical and radiological features in this fetus, together with the finding of complete sex reversal, are typical of those seen in campomelic dysplasia as delineated by Houston et al in their review of 97 patients. They, in fact, concluded that the term 'syndrome' was preferable to 'dysplasia' in vew of the non-skeletal anomalies, although dysplasia remains the word most often used in medical publications. The presence of the characteristic long bone changes at 18 to 20 weeks in this fetus and in others $^{3}$ confirms that the tibial angulation is likely to be a primary abnormality rather than secondary to intrauterine pressure.

Autosomal recessive inheritance has been proposed as the probable mode of transmission on the basis of reports of parental consanguinity and affected sibs, although the segregation ratio appears to be less than $0.25^{1}$ indicating that there may be a high rate of early pregnancy loss or that other genetic mechanisms may be involved. Cooke $e t a l^{4}$ described a case with sex reversal in a child with a paternally inherited and apparently balanced reciprocal translocation, $\mathrm{t}(5 ; 8)$ (q33.1;q21.4). More recently, Maraia et $a l$ reported an affected female with a de novo paracentric inversion of $17 \mathrm{q}$, the apparent breakpoints being at $\mathrm{q} 12$ and q25. These authors conceded that these represented 'crude estimations'.

In the case now presented we are confident that the breakpoint on chromosome 17 lies in the region q23-24, and we are prompted to speculate that this rearrangement arising in the germ cell from one parent has unmasked constitutional heterozygosity in the other parent. This coalescence of interest in the long arm of chromosome 17 strongly points towards this being the location of the CD gene, and indicates that further attention should be focused on loci such as those of the growth hormoneplacental lactogen gene family which are known to be located in this region. ${ }^{5}$

1 Houston CS, Opitz JM, Spranger JW, et al. The campomelic syndrome: review, report of 17 cases, and follow-up on the currently 17 -year-old boy first reported by Maroteaux et al in 1971. Am ₹ Med Genet 1983;15:3-28.

2 Maraia R, Saal HM, Wangsa D. A chromosome $17 \mathrm{q}$ de novo paracentric inversion in a patient with campomelic dysplapia; case report and etiologic hypothesis. Clin Genet 1991;39:401-8.

3 Gillerot Y, Vanheck C-A, Foulon M, Podevain A, Koulischer L. Campomelic syndrome: manifestations in a 20 week fetus and case history of a 5 year old child. $A m \mathcal{F} M e d$ Genet 1989;34:589-92.

4 Cooke CT, Mulcahy MT, Cullity GJ, Watson M, Sprague P. Campomelic dysplasia with sex reversal: morphological Campomelic dysplasia with sex rersal: morphological 17:526-9.

5 Harper ME, Barrera-Saldana HA, Saunders GF. Chromosomal localization of the human placental lactogen-growth hormone gene cluster to $17 \mathrm{q} 22-24$. Am 7 Hum Genet 1982; 34:227-34. 